Article

\title{
New Source of 3D Chitin Scaffolds: The Red Sea \\ Demosponge Pseudoceratina arabica (Pseudoceratinidae, Verongiida)
}

\author{
Lamiaa A. Shaala ${ }^{1,2, *}$, Hani Z. Asfour ${ }^{3}$, Diaa T. A. Youssef ${ }^{4,5}$ (D, \\ Sonia Żółtowska-Aksamitowska ${ }^{6,7}$, Marcin Wysokowski ${ }^{6,7}$, Mikhail Tsurkan ${ }^{8}$ (D), \\ Roberta Galli ${ }^{9}$ (D), Heike Meissner ${ }^{10}$, Iaroslav Petrenko ${ }^{7}$, Konstantin Tabachnick ${ }^{11}$, \\ Viatcheslav N. Ivanenko ${ }^{12}$, Nicole Bechmann ${ }^{13}$ (D), Lyubov V. Muzychka ${ }^{14}$, Oleg B. Smolii ${ }^{14}$, \\ Rajko Martinović ${ }^{15}$, Yvonne Joseph ${ }^{7}$ (D), Teofil Jesionowski ${ }^{6}$ and Hermann Ehrlich ${ }^{7, *}$ \\ 1 Natural Products Unit, King Fahd Medical Research Centre, King Abdulaziz University, \\ Jeddah 21589, Saudi Arabia \\ 2 Suez Canal University Hospital, Suez Canal University, Ismailia 41522, Egypt \\ 3 Department of Medical Parasitology, Faculty of Medicine, Princess Al-Jawhara Center of Excellence in \\ Research of Hereditary Disorders, King Abdulaziz University, Jeddah 21589, Saudi Arabia; \\ hasfour@kau.edu.sa \\ 4 Department of Natural Products, Faculty of Pharmacy, King Abdulaziz University, \\ Jeddah 21589, Saudi Arabia; dyoussef@kau.edu.sa \\ Department of Pharmacognosy, Faculty of Pharmacy, Suez Canal University, Ismailia 41522, Egypt \\ 6 Institute of Chemical Technology and Engineering, Faculty of Chemical Technology, Poznan University of \\ Technology, Poznan 60965, Poland; soniazolaks@gmail.com (S.Ż.-A.); \\ marcin.wysokowski@put.poznan.pl (M.W.); teofil.jesionowski@put.poznan.pl (T.J.) \\ 7 Institute of Electronics and Sensor Materials, Technische Universität Bergakademie-Freiberg, \\ Freiberg 09599, Germany; iaroslavpetrenko@gmail.com (I.P.); yvonne.joseph@esm.tu-freiberg.de (Y.J.) \\ 8 Leibniz Institute of Polymer Research Dresden, Dresden 01069, Germany; tsurkanmv@gmail.com \\ 9 Clinical Sensoring and Monitoring, Department of Anesthesiology and Intensive Care Medicine, Faculty of \\ Medicine, Technische Universität Dresden, Dresden 01307, Germany; roberta.galli@tu-dresden.de \\ 10 Department of Prosthetic Dentistry, Faculty of Medicine, Technische Universität Dresden, \\ Dresden 01307, Germany; heike.meissner@uniklinikum-dresden.de \\ 11 P.P. Shirshov Institute of Oceanology, Russian Academy of Sciences, Moscow 117997, Russia; \\ tabachnick@mail.ru \\ 12 Department of Invertebrate Zoology, Biological Faculty, Lomonosov Moscow State University, \\ Moscow 119992, Russia; ivanenko.slava@gmail.com \\ 13 Institute of Clinical Chemistry and Laboratory Medicine, University Hospital Carl Gustav Carus at the \\ Technische Universität Dresden, Dresden 01307, Germany; nicole.bechmann@uniklinikum-dresden.de \\ 14 V.P. Kukhar Institute of Bioorganic Chemistry and Petrochemistry, National Academy of Science of Ukraine, \\ Kiev 02094, Ukraine; lmuzychka@rambler.ru (L.V.M.); smolii@bpci.kiev.ua (O.B.S.) \\ 15 Institute of Marine Biology, University of Montenegro, Kotor 85330, Montenegro; rajko.mar@ucg.ac.me \\ * Correspondence: 1shalla@kau.edu.sa (L.A.S.); hermann.ehrlich@esm.tu-freiberg.de (H.E.)
}

Received: 7 January 2019; Accepted: 30 January 2019; Published: 1 February 2019

\begin{abstract}
The bioactive bromotyrosine-derived alkaloids and unique morphologically-defined fibrous skeleton of chitin origin have been found recently in marine demosponges of the order Verongiida. The sophisticated three-dimensional (3D) structure of skeletal chitinous scaffolds supported their use in biomedicine, tissue engineering as well as in diverse modern technologies. The goal of this study was the screening of new species of the order Verongiida to find another renewable source of naturally prefabricated 3D chitinous scaffolds. Special attention was paid to demosponge species, which could be farmed on large scale using marine aquaculture methods. In this study, the demosponge Pseudoceratina arabica collected in the coastal waters of the Egyptian Red Sea was examined as a potential source of chitin for the first time. Various bioanalytical tools including scanning electron
\end{abstract}


microscopy (SEM), fluorescence microscopy, FTIR analysis, Calcofluor white staining, electrospray ionization mass spectrometry (ESI-MS), as well as a chitinase digestion assay were successfully used to confirm the discovery of $\alpha$-chitin within the skeleton of P. arabica. The current finding should make an important contribution to the field of application of this verongiid sponge as a novel renewable source of biologically-active metabolites and chitin, which are important for development of the blue biotechnology especially in marine oriented biomedicine.

Keywords: chitin; scaffolds; biological materials; demosponges; Pseudoceratina arabica

\section{Introduction}

Structural aminopolysaccharide chitin is one of the oldest biopolymers due to its presence in fungi which appeared on our planet around 2.4 billion years ago [1]. In 1811, Henri Braconnot discovered chitin in the form of an alkali-resistant fraction during his studies on higher fungi and, consequently, termed it as fungine (for review see [2]). The currently used term chitin, however, has been proposed in 1823 by Auguste Odier who used beetle cuticles to isolate similar biomaterial during alkali treatment with hot $\mathrm{KOH}$ solutions [3]. Chitin has been found in skeletal structures of diverse unicellular organisms (yeasts, protists) and invertebrate organisms (corals, annelids, molluscs, arthropods) with exception of crustose coralline algae; cell walls of diatoms and skeletons of sponges (see for review $[4,5]$ ). The existence of chitin within the marine demosponges and glass sponges' skeletons was reported for the first time only in 2007 [6,7]. The first report on chitin identification in siliceous cell walls (frustules) of diatoms was carried out in 2009 [8]. Intriguingly, the presence of chitin in crustose coralline algae has been described in 2014 [9]. Nowadays, chitin has been reported in 17 species of marine [10] and in two species of freshwater sponges [11,12]. One of the special characteristics of poriferan chitin is the 3D fibrous nature, which has been recognized as a naturally prefabricated tubular scaffold that follows the morphology especially of keratosan demosponges [13-15]. These unique 3D architectures of such scaffolds are typical for representatives of the Verongiida order (subclass Verongimorpha, class Demospongiae) and open perspectives for their applications in waste treatment [16], tissue engineering $[14,17,18]$, electrochemistry [19] as well as extreme biomimetics [2,20-23]. Due to the fact that manufacturing of fungi, as well as crustaceans chitin into 3D sponge-like scaffolds, is difficult and expensive, the extensive research of species-specific morphology and structure of the chitin-scaffolds of sponge origin as "ready to use" materials still remain important for practical applications.

Representatives of Verongiida demosponges contain aplystane-type and bromotyrosine-derived secondary metabolites, which is a unique feature within Demospongiae. This is a very distinct chemotaxonomic marker for all members of the order Verongiida [24-26]. It has been proved that bromotyrosine-derived alkaloids possess antimicrobial, antifungal, cytotoxic, and antimalarial activity (for review see [27-34]). Interestingly, only nudibranchs represent the natural predator of the verongiid sponges [35]. As reported previously [36], some of bromotyrosines also showed anti-chitinase activity. Consequently, it was suggested that bromotyrosine related compounds localized within chitinous skeletons of verongiid sponges can inhibit the chitinases of bacterial and fungal origins and in this way protect the integrity of sponge skeleton [13].

So far, only two representative species of the Verongiida order exist in the Red Sea, namely Pseudoceratina arabica and Suberea mollis. Both sponges have been extensively investigated by our group to identify their bioactive compounds. Recently, several bromotyrosine alkaloids and halogenated compounds with different biological activities have been reported from these two sponges [27-31,37,38]. Due to the ability of diverse chitin-producing sponges to grow under marine ranching conditions (see for overview [39]), poriferan chitin constitutes a renewable source of such unique naturally occurring scaffolds. This encouraged studies on monitoring of novel demosponge species with chitinous 
skeletons. Therefore, this study focused on the bromotyrosines producing Red Sea demosponge Pseudoceratina arabica (Figure 1) where the presence of chitin has never been reported before.

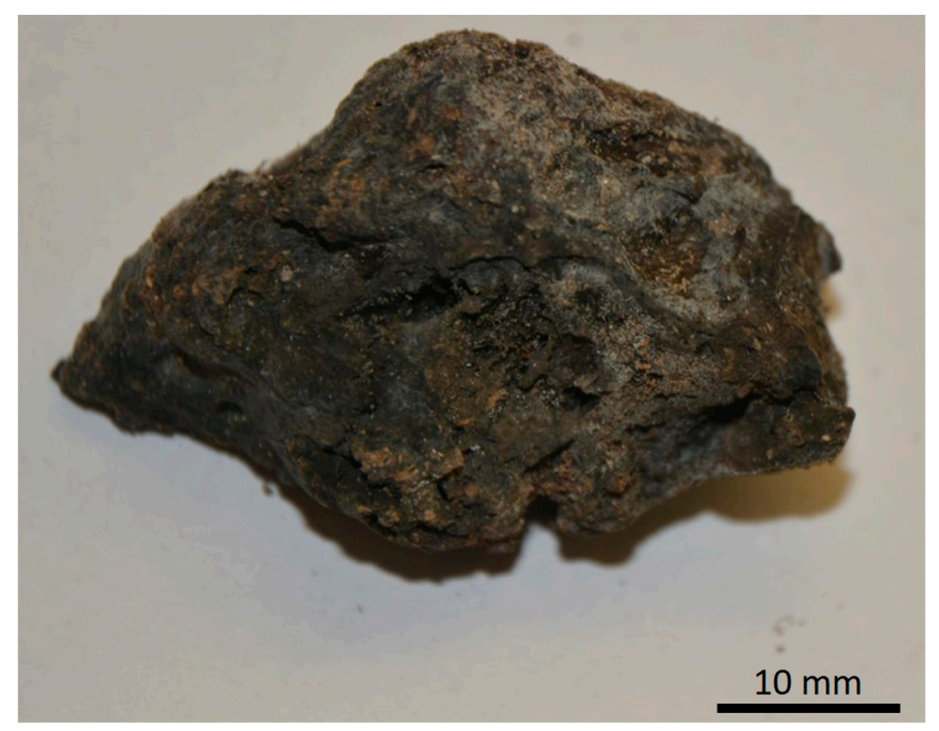

Figure 1. The fragment of the dried specimens of P. arabica demosponge used in this study.

\section{Results}

Figure 2 clearly shows that the alkali treatment resulted in depigmented, protein-free, fibrous scaffolds with residual siliceous spicules and foreign, sandy microparticles within the fibers (Figure 3). Observations of these contaminants into the $\mathrm{NaOH}$-treated fragments of P. arabica support our previous suggestion about the allochronic origin of sponges from Pseudoceratinidae family [33].

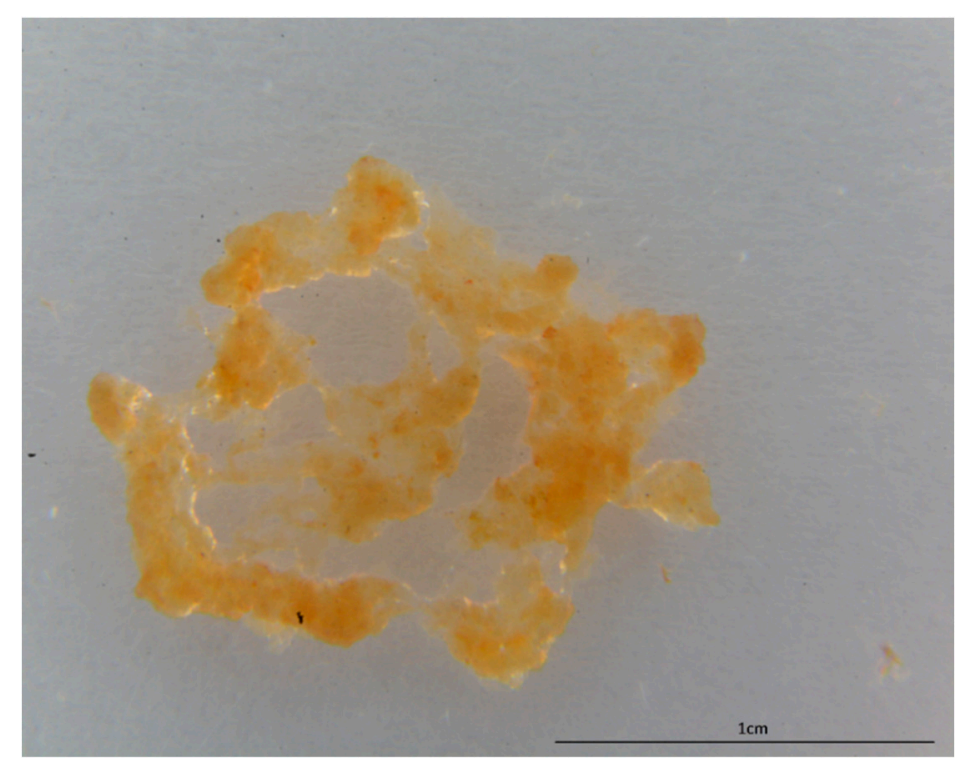

Figure 2. Completely demineralized and pigment-free scaffolds isolated from the sponge P. arabica. 

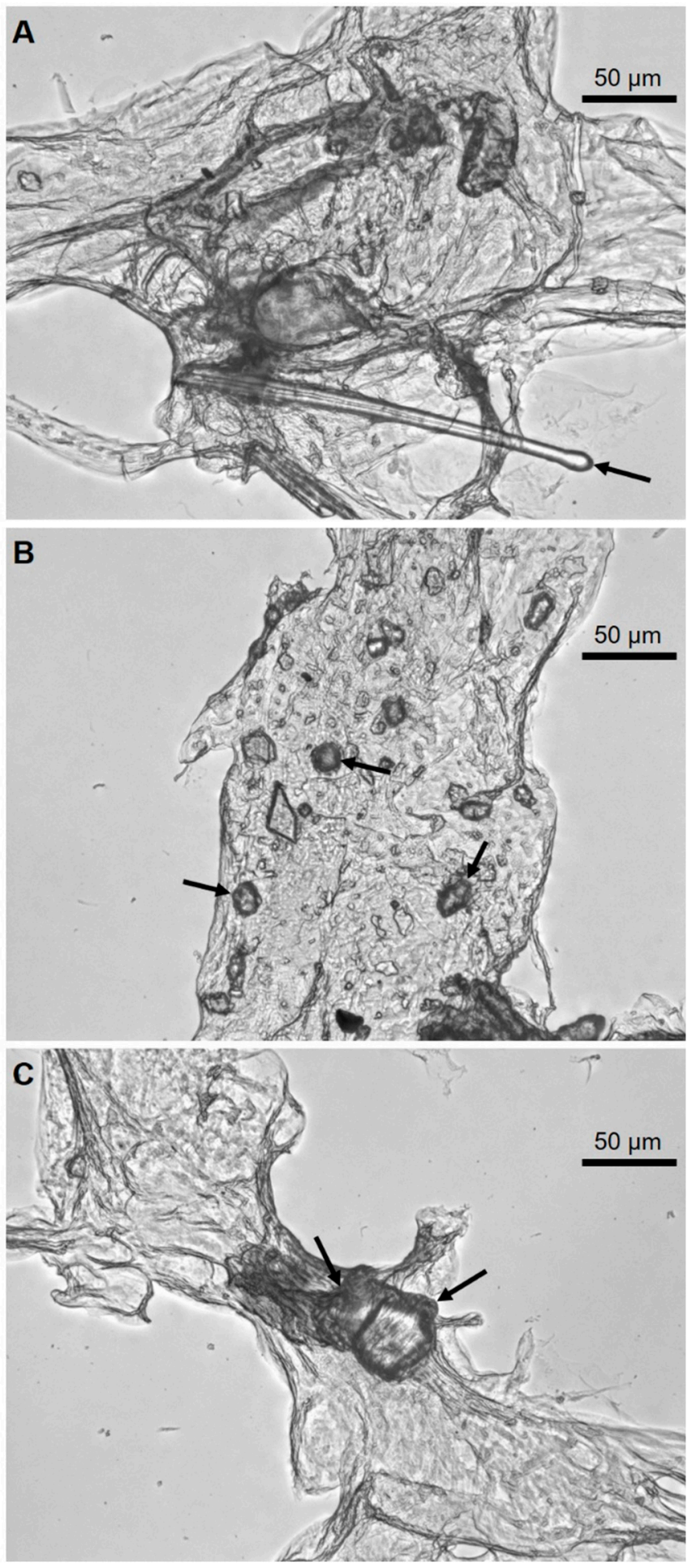

Figure 3. Alkali-treated fibers of P. arabica under the optical microscope showing foreign spicules (A) and microparticles of sand (B, C) (arrows).

SEM microphotographs of the scaffolds isolated from P. arabica before (Figure 4) and after (Figure 5) HF-treatment show that only treatment using diluted HF water solution leads to dissolution and removal of sand microparticles as well as spicules and result in silica-free, pure, microfibers with high structural integrity, as observed before in other verongiid sponges $[6,13,15,40]$ (Figure 5). These results were also confirmed using light as well as fluorescent microscopy (Figure 6). 

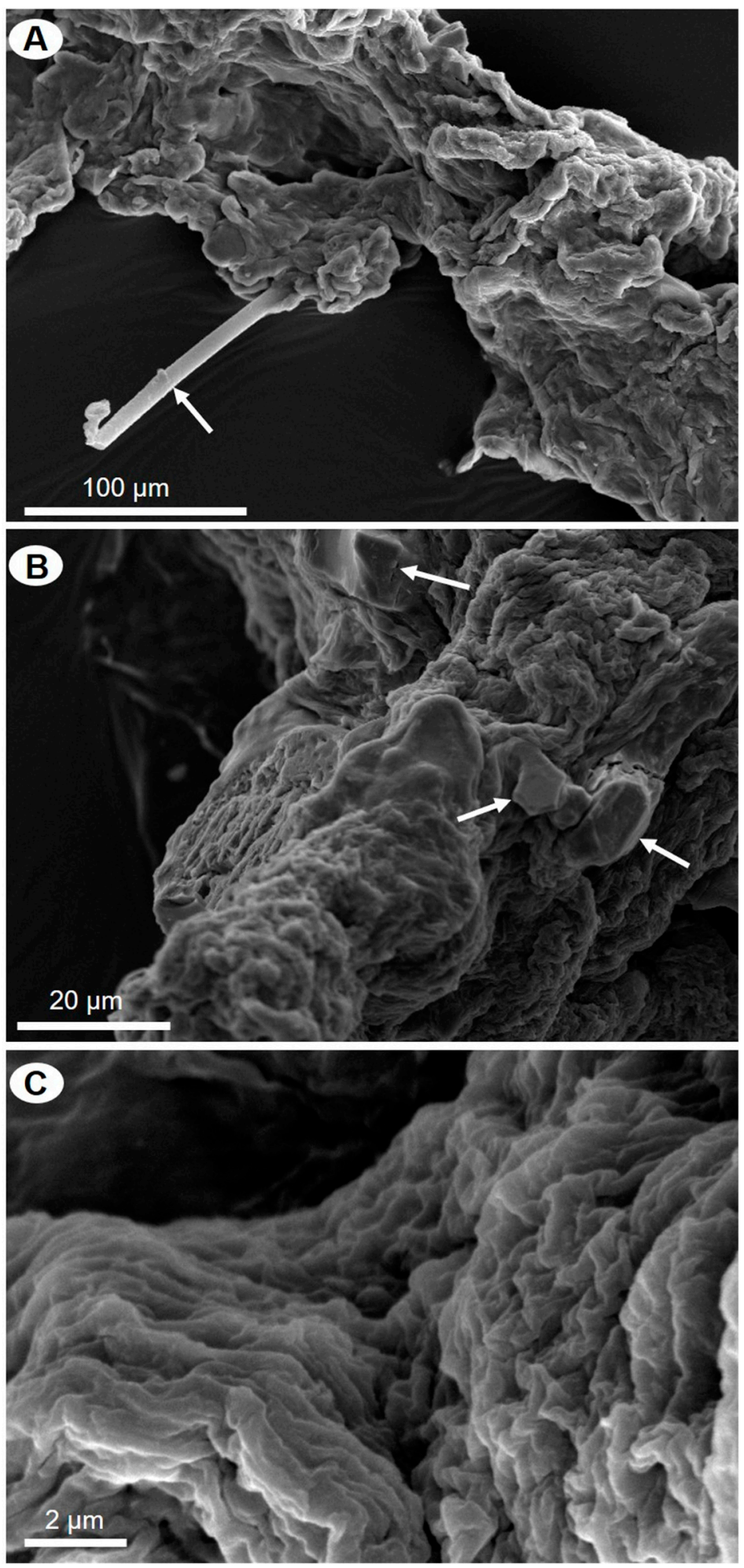

Figure 4. SEM images of alkali-treated skeletal fibers of P. arabica. Microparticles of siliceous foreign sponge spicules (A) and sand particles (B) are marked with arrows. Some parts of partially demineralized fibers remain to be free from foreign particles $(\mathbf{C})$. 

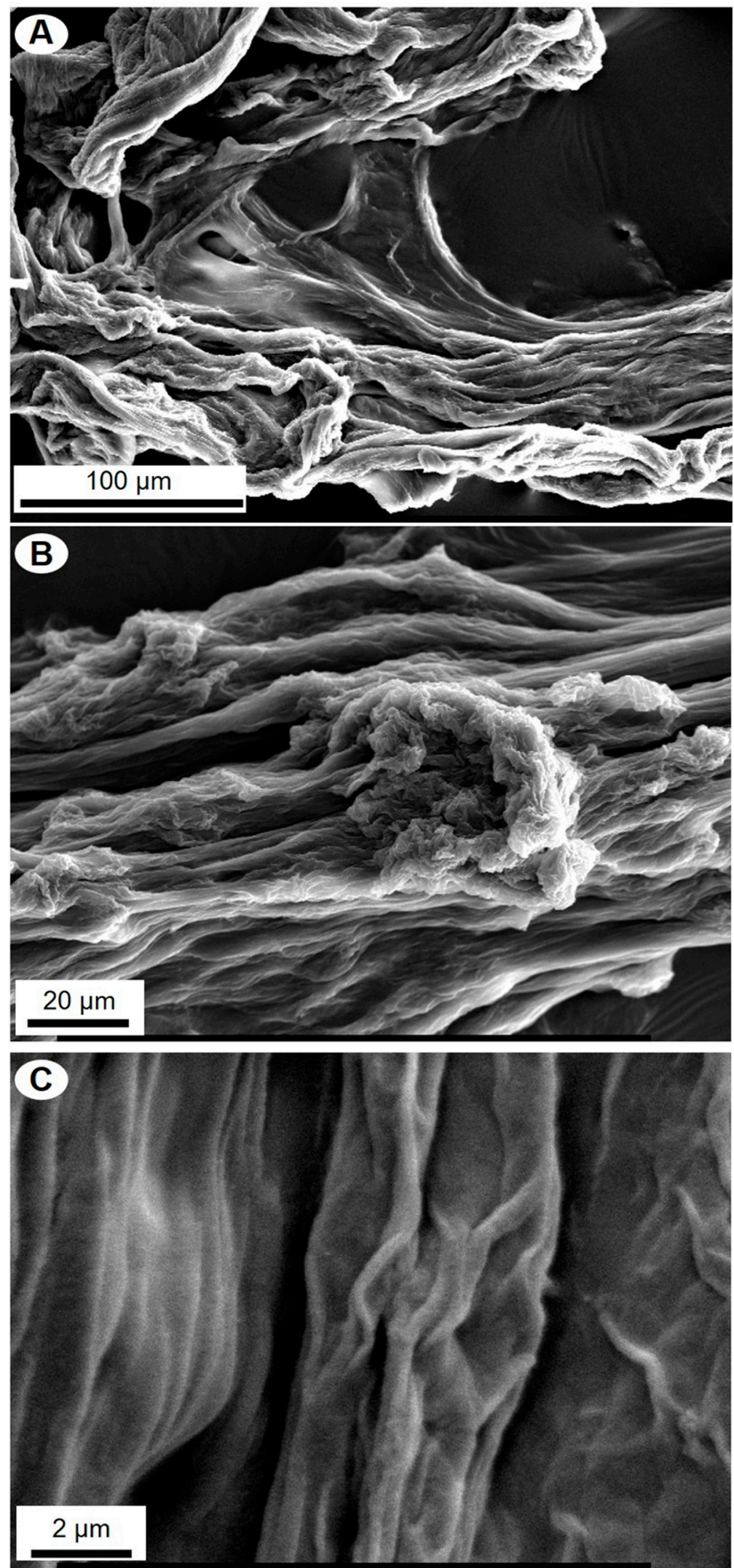

Figure 5. SEM images of P. arabica fibers after desilicification in 10\% of HF under different levels of magnification $(\mathrm{A}-\mathrm{C})$. 

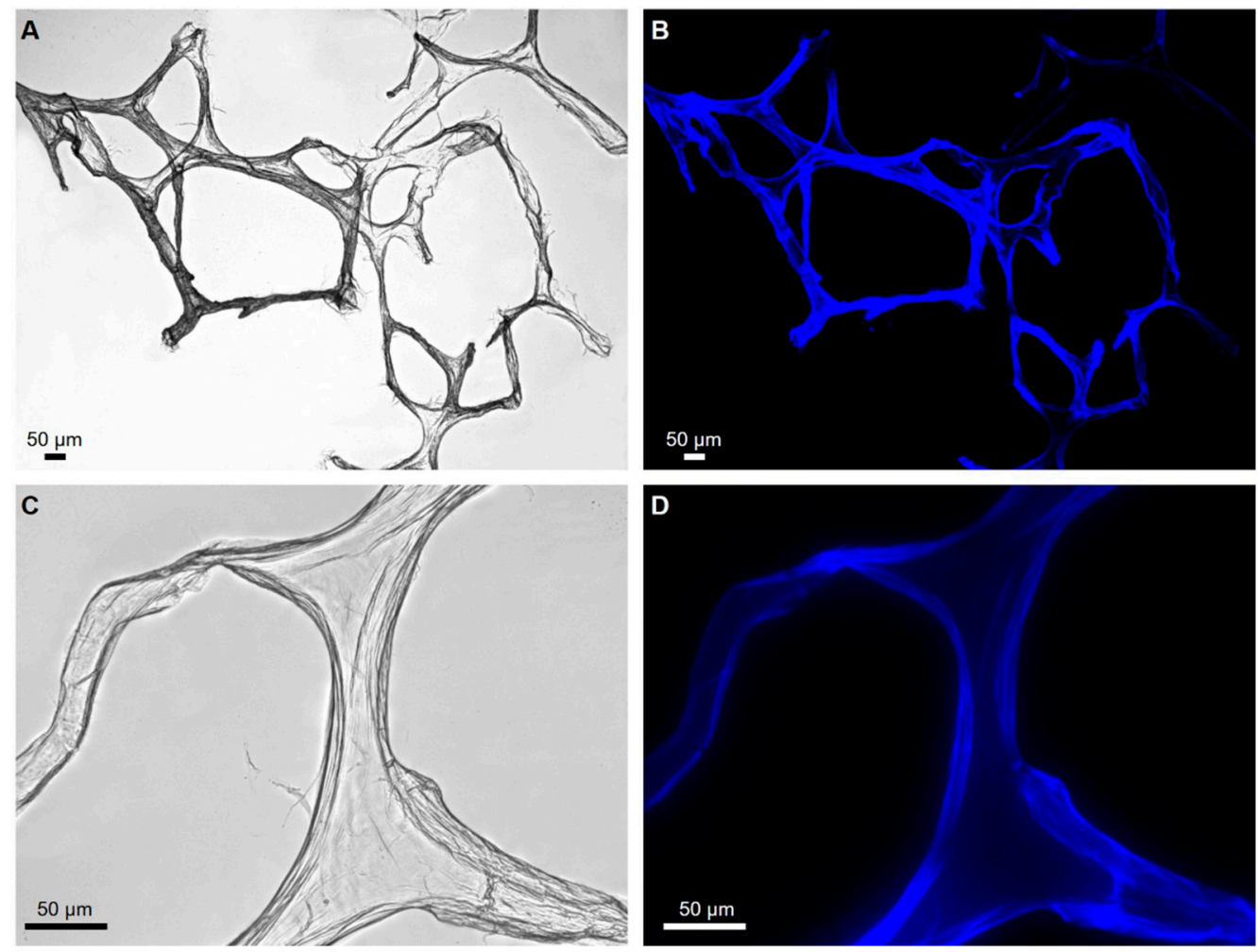

Figure 6. Light microscopy (A,B) and fluorescence (C,D) microscopy images of P. arabica fibers after desilicification in $10 \% \mathrm{HF}$ lacking of spicules and other foreign contaminants in investigated fibers.

Typically, Calcofluor white staining (CFW) was used as the first stage of chitin identification in completely demineralized (including HF-based treatment) sponge skeletons. This fluorescent dye is commonly used for staining $\beta-(1 \rightarrow 3)$ and $\beta-(1 \rightarrow 4)$ linked polysaccharides including chitin. Consequently, after binding to polysaccharides, CFW dye exhibits bright blue light under UV excitations [41].

Examination of the scaffolds isolated from P. arabica after CFW staining using fluorescent microscopy demonstrate strong fluorescence under light exposure time as short as $1 / 4800 \mathrm{~s}$ (Figure 7B). Similar conclusions were reported previously for chitin isolated from sponges of marine $[6,10,15,32,33,40]$ as well as freshwater [12] origin and fossilized chitin-containing remains $[11,41]$.
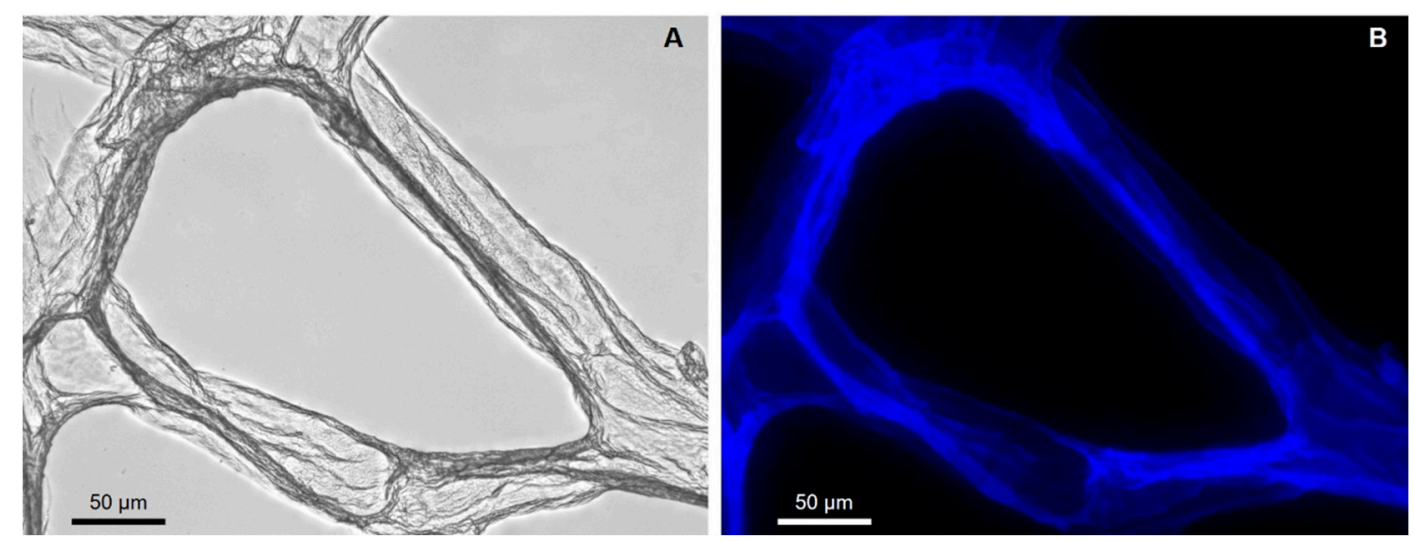

Figure 7. Completely purified fibers of P. arabica after CFW staining: (A) light microscopy image and (B) fluorescence microscopy image of the same location (light exposure time 1/4800) confirm the chitinous nature of the fibers. 
More precise methods were applied to study in details the presence and identification of chitin in isolated scaffolds. FTIR spectroscopy is considered as an effective technique for structural analysis of different polysaccharides including chitin. Recently, FTIR analysis was successfully used to obtain information about of type of polymorph form of chitin [42].

The acquired FTIR spectra of demineralized scaffolds of $P$. arabica and standard $\alpha$-chitin are presented in Figure 8. Between 1700 and $1500 \mathrm{~cm}^{-1}$, the different signatures characteristic for chitin polymorphs were observed. In this amidic moiety region, the investigated sample showed strong band related to the stretching vibrations of $\mathrm{C}=\mathrm{O}$ group characteristic for band I of the amidic moiety. This band, registered for studied sample, possessed twin peaks at 1651 and $1633 \mathrm{~cm}^{-1}$, which is related with the presence of two types of carbonyl groups within the chitin chain, and it is also typical for $\alpha$-chitin. The first peak derives from the specific intermolecular hydrogen bond of carbonyl group and hydroxymethyl group on the next chitin residue in the same chain. The second peak is a result of the intramolecular hydrogen bonds of carbonyl with the amide groups. Additionally, in the purified sponge chitin sample, as well as in the $\alpha$-chitin standard, the characteristic intense band at $v_{\max } 948 \mathrm{~cm}^{-1}$ which is referred to $\gamma \mathrm{CH}_{\mathrm{x}}$ bond was observed. Moreover, the $\alpha$-chitin characteristic band assigned to $\beta$-glycosidic bond at $895 \mathrm{~cm}^{-1}$ is well visible in the studied samples. However, it should be noted that the characteristic bands for $\mathrm{CaCO}_{3}\left(855-876 \mathrm{~cm}^{-1}\right)$ and $\mathrm{SiO}_{2}\left(720 \mathrm{~cm}^{-1}\right)$ were not observed in the spectrum of $P$. arabica, suggesting that procedure of chitin isolation resulted in chitin of high purity. Additionally, the comprehensive analysis of acquired spectra shows that recorded bands correspond with those referred in the $\alpha$-chitin reference sample.

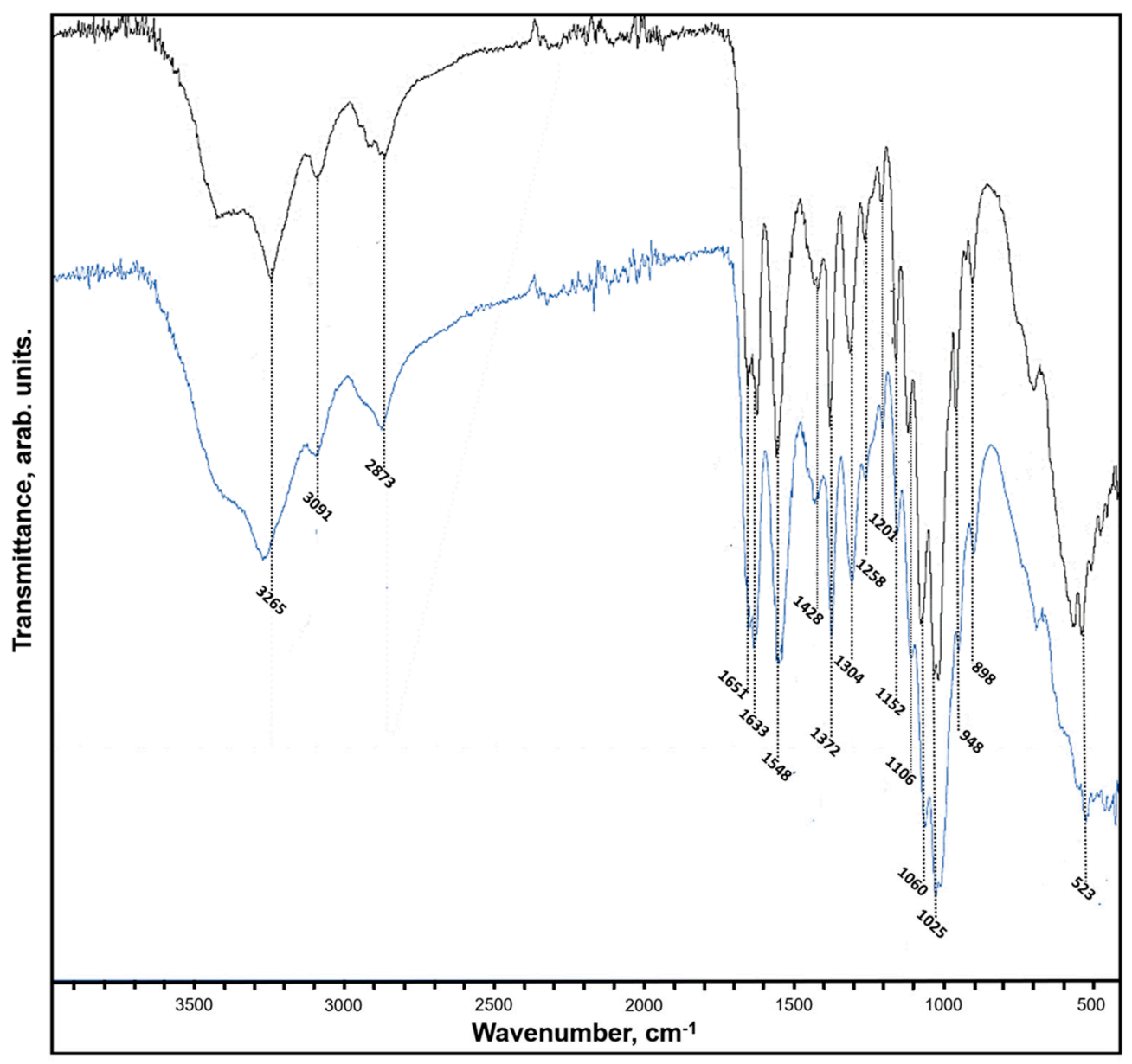

Figure 8. FTIR spectra of the chitin isolated from P. arabica compared to standard $a$-chitin. 
Figure 9 shows the Raman spectrum of chitin isolated from P. arabica compared with the spectrum of the $\alpha$-chitin reference. Characteristic bands for $\alpha$-chitin can be found in the spectrum of the isolated chitin within the spectral resolution of the measurement. The existence of two bands characteristic to amine band I at $v_{\max } 1657$ and $1624 \mathrm{~cm}^{-1}$ as well as intense band related to the $\beta$-glycosidic bond at $v_{\max } 895 \mathrm{~cm}^{-1}$ clearly indicate that chitin isolated from P. arabica is of $\alpha$ isomorph. Moreover, the bands in the spectrum are in good agreement with previously published data $[5,10,43,44]$.

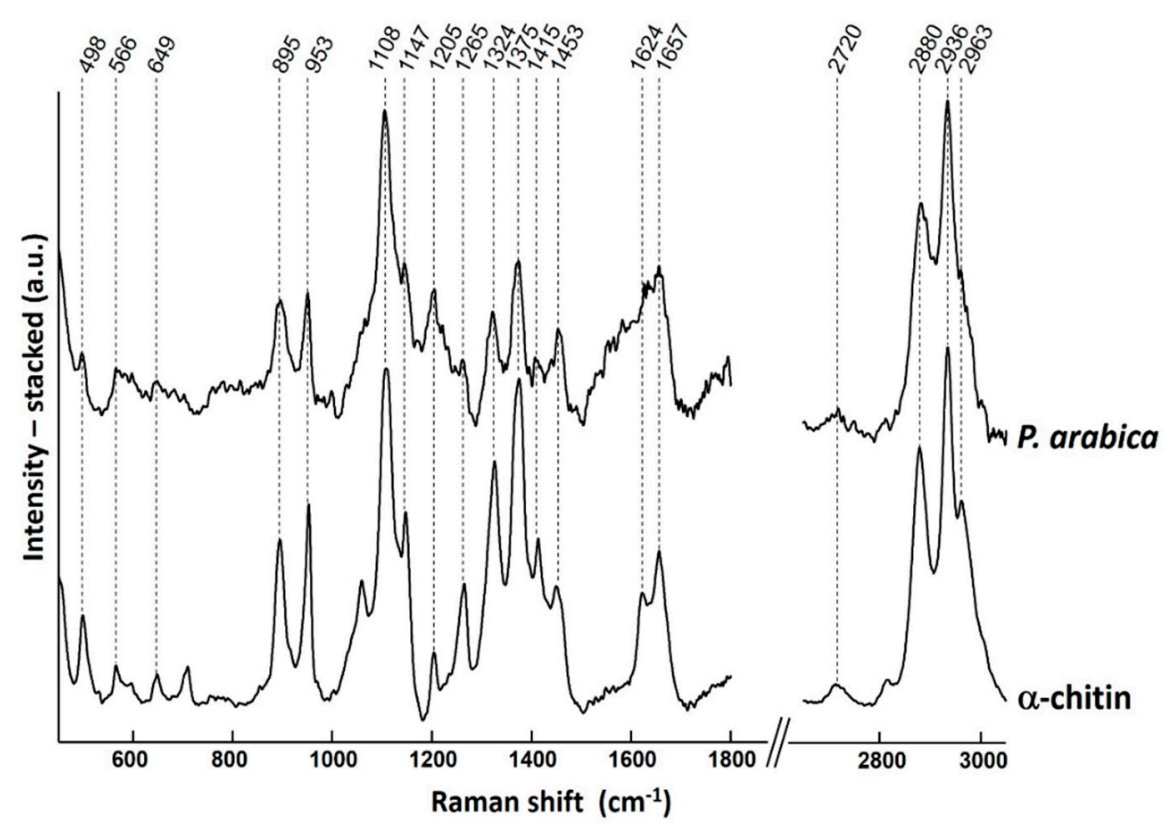

Figure 9. A Raman spectrum of chitin isolated from P. arabica compared with the spectrum of reference $\alpha$-chitin. The bands of $P$. arabica are in good agreement with those of $\alpha$-chitin standard within the spectral resolution of the measurements.

Previously, in order to confirm the presence of chitin in diverse sponges, the chitinase digestion test has been successfully applied $[6,10,15,32,33,40]$. This enzyme has unique ability to decompose chitin into low-molecular oligomers such as $N$-acetyl- $D$-glucosamine (GlcNAc). Therefore, the action of chitinase leads to the loss of chitin integrity and the release of residual chitin microfibers of steadily decreasing size. The changes in the structure of treated fibers can be observed using light microscopy (Figure 10). This test is unequivocal and provides additional confirmation of the successful chitin isolation from the sponge under study here.

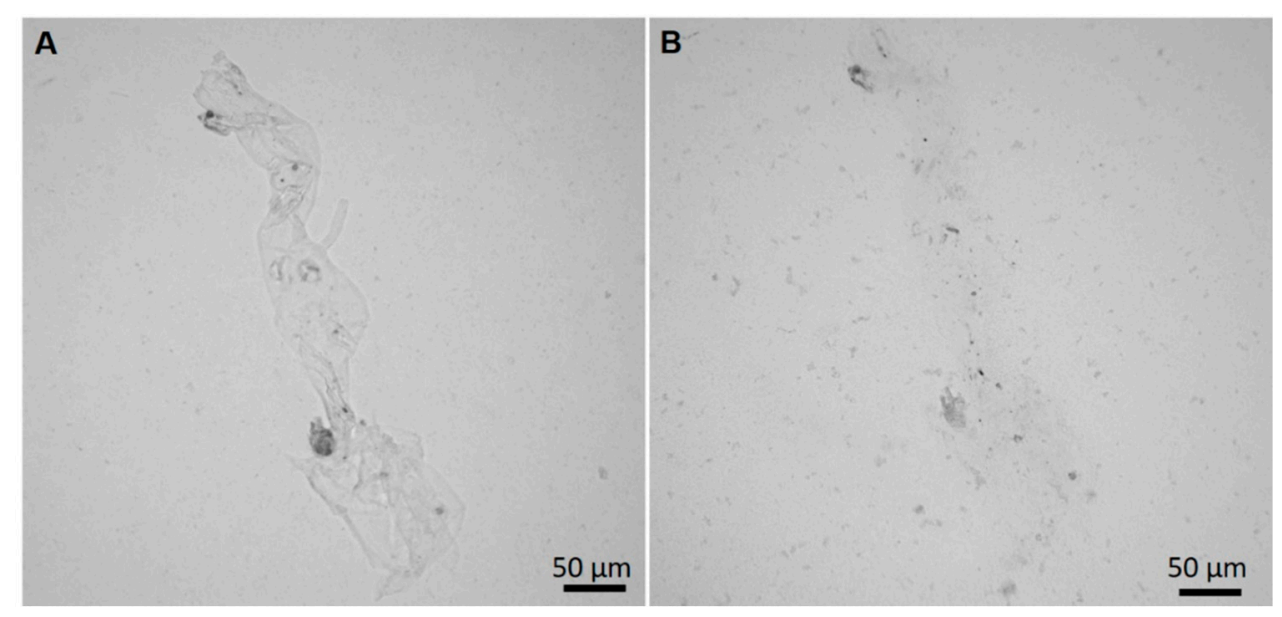

Figure 10. Results of chitinase digestion test on the purified skeletal fibers of P. arabica. Fibers before the digestion (A) and after $2 \mathrm{~h}$ of treatment with chitinase solution (B) are well visible. 
D-glucosamine $(\mathrm{dGlcN})$ is the product of chitin's acidic hydrolysis which can be readily identified by electrospray-ionization mass spectroscopy (ESI-MS) measurements. Thus, ESI-MS spectroscopy becomes a standard method for chitin identification which usability was shown in complex organisms [40,45,46] and even in 505-million-year-old chitin-containing fossil remnants [47].

In the positive ESI-MS spectra, D-glucosamine $(\mathrm{dGlcN})$ standard revealed several main ion peaks with $m / z=162.08,180.09,202.07,359.17$, and 381.15 (Figure 11). The ion peak at $m / z=180.09$ and 202.07 correspond to a $[\mathrm{M}+\mathrm{H}]^{+}$and $[\mathrm{M}+\mathrm{Na}]^{+}$species with molecular weight of 179.09 which is dGlcN molecule (calculated: 179.1 ). The ion peak at $m / z=161.85$ corresponds to a $[\mathrm{M}+\mathrm{H}]^{+}$specie with molecular weight of 160.85 that is dGlcN ion $\left[\mathrm{M}-\mathrm{H}_{2} \mathrm{O}+\mathrm{H}\right]^{+}$without one water molecule (calculated: 161.1). There are also week ion peaks at $m / z=359.17$ and 381.15 corresponding to $[2 \mathrm{M}+\mathrm{H}]^{+}$and $[2 \mathrm{M}+\mathrm{Na}]^{+}$species which are proton- or sodium-bound dGlcN noncovalent dimmer. The ESI-MS spectra of the P. arabica hydrolysate has revealed nearly identical ion peaks to those of the $D$-glucosamine standard signal composition (Figure 12). This result clearly demonstrates the presence of dGlcN in the hydrolysate and correspondingly chitin in the sample.

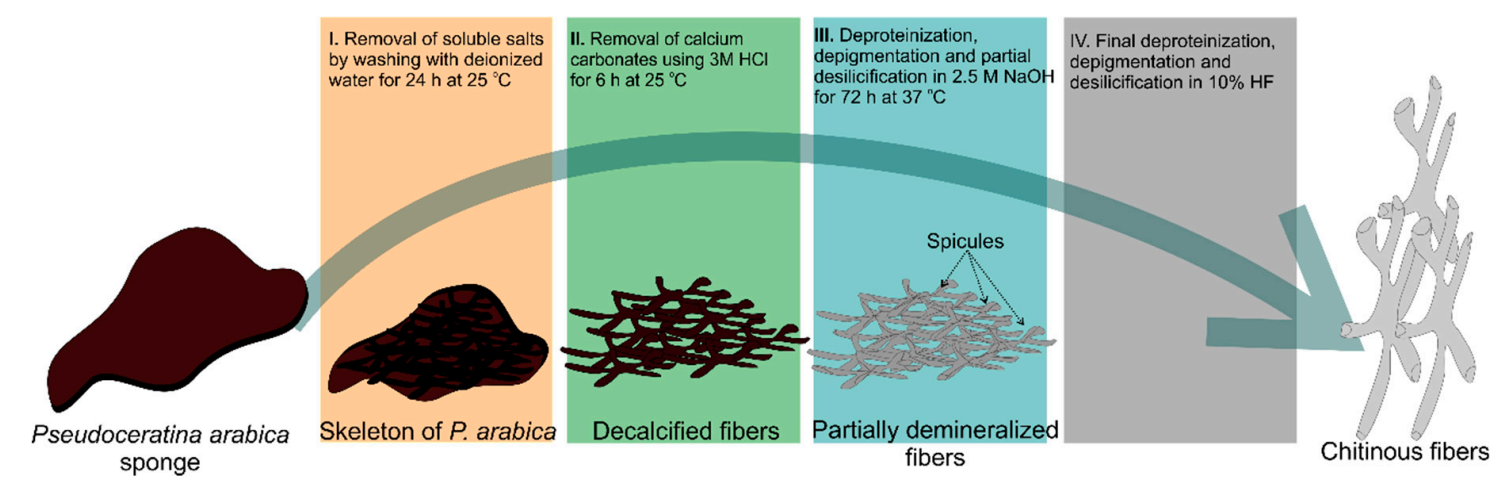

Figure 11. Schematic diagram showing the step-by-step procedure of chitin isolation from the skeleton of P. arabica.
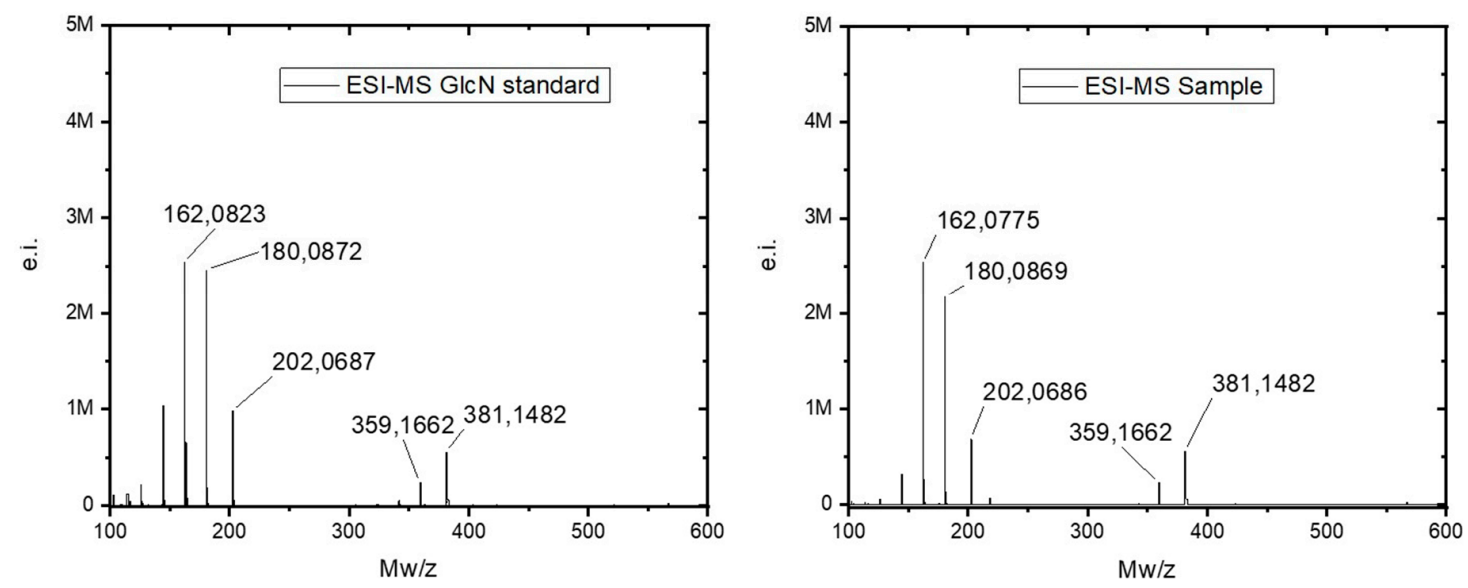

Figure 12. The positive ESI-MS spectra of D-glucosamine (dGlcN) standard (left) and of acid-hydrolyzed chitin (right) from P. arabica.

\section{Discussion}

Seas and oceans are a huge source of various invertebrate animals with potential to be used in biomedicine. For this reason, these organisms are frequently being tested for the presence of various useful products (unique secondary metabolites, biopolymers and biological materials), and many of them have been found in marine sponges. The order Verongiida has been recognized to be divided into four families, which differ in the structure and composition of skeletal fibers [48,49]. The largest verongiid family is Aplysinidae (52 species from three genera: Aiolochroia, Aplysina, and Verongula). 
This family is characterized by an anastomosing fiber skeleton with both pith and bark elements. The second largest verongiid family is Ianthellidae (21 species in four genera: Anomoianthella, Hexadella, Ianthella, and Vansoestia). The presence of eurypylous choanocyte chambers is a feature distinguishing this family from the others verongiids. Aplysinellidae includes 17 species in three genera (Aplysinella, Porphyra, and Suberea) with dendritic fiber skeleton possessing both pith and bark elements, which are typical morphological features characteristic for representatives of this family. The verongiid P. arabica (Keller, 1889) that has been investigated in this study belongs to the family Pseudoceratinidae, which is currently including four species representing the only genus Pseudoceratina. Representatives of this family are characterized by a dendritic fiber skeleton with only pith elements. Interestingly, sponges of the genus Pseudoceratina are assumedly the richest sources of pharmacologically active alkaloids with diverse chemical skeletons within the order Verongiida [33]. Among various secondary metabolites isolated from Pseudoceratina species are: moloka'iamine derivatives, phenolic halogenated compounds, psammaplysins, pseudoceratinamide A and B, ceratinines, moloka'iakitamide, aplysterol, and aplysamine [33]. To date, a variety of secondary metabolites obtained from P. arabica have been purified using the solvent extraction method. Surprisingly, there are no literature reports on the extraction of these metabolites using the alkaline-based solution as well as about structural stability of such biomolecules at $\mathrm{pH}$ above 7 . Alkaline stepwise extraction procedures were recently reported as effective methods for isolation of chitin-based scaffolds with bromotyrosines from other representatives of the order Verongiida and to "squeeze the full potential" of marine sponges [39]. However, it is necessary to prove, the pharmacological and biotechnological potential of the Red Sea verongiid sponges especially because of the recently published intriguing results concerning anti-tumorigenic and anti-metastatic activity of Aeroplysinin- 1 which is one of the main bromotyrosine derivatives extracted from Verongiida [34]. All Verongiida sponge samples analyzed until now were found to exhibit a chitin-based scaffold, and here it was proved that $P$. arabica is the new example of chitin-containing sponge from this order. Apart from the bioactive metabolites of P. arabica, which are excellently described in the literature, here it was strongly demonstrated that this marine sponge can be effectively used also as a source of naturally prefabricated 3D chitinous scaffold with open-pore structure. Unfortunately, there is still lack of information concerning the interrelationships between the secondary metabolites and chitinous skeleton of $P$. arabica, especially with respect to their localization within so called spherulous cells. However, it known that spherulous cells are rich on bromotyrosines and have been found within skeletal fibres of verongiids [50]. The questions about the role of bromotyrosines in regeneration of chitinous skeleton as well as the growth rate of this species are still open. However, these data are crucial for the future estimation of the biotechnological, biomedical and pharmaceutical potential of $P$. arabica in the region.

It is worth to mention that, the 3D macroporous biomaterials of sponge origin gain a particular interest in tissue engineering, water purification, catalysis, and electrochemistry [51]. Preliminary research done with the use of corresponding 3D chitinous-scaffolds isolated from A. aerophoba [17] and Ianthella basta [18] confirm their biocompatibility with human mesenchymal stromal cells; supporting their adhesion, viability, growth, and proliferation. Additional, useful features of chitinous scaffolds of poriferan origin are their simplicity and ease of isolation. Calculated swelling capacity for chitinous matrices isolated from P. arabica is equal to $255 \pm 8 \%$. There are no doubts that comparative studies on interconnected porosity and swelling ability between chitinous matrices of P. arabica and that from other verongiid species $[17,18]$ should be carried out. Consequently, the discovery of chitin in other members of the genus Pseudoceratina would be the next stage in the evaluation of the possibility to accept these organisms as a new source of 3D chitin scaffolds with macroporosity which range between 150-350 $\mu \mathrm{m}$ for biomedical applications. We suggest that the opportunity for ex situ cultivation of P. arabica can be an important advantage, which enables the use of this sponge for large scale applications in diverse advanced technologies. 


\section{Materials and Methods}

\subsection{Collection of Samples}

Specimens of marine sponge Pseudoceratina arabica (Keller, 1889) (Porifera: Demospongiae: Verongiida: Pseudoceratinidae) described initially as Psammaplysilla arabica Keller, 1889 were collected by hands using SCUBA from the southern part of the Egyptian Hurghada (N 27 $02^{\prime} 46.8^{\prime \prime}$ E $33^{\circ} 54^{\prime} 21.4^{\prime \prime}$ ) in July 2017 at depths up to $25 \mathrm{~m}$. The yellowish green encrusting sponge with its conulose surface measuring about $1-2 \mathrm{~cm}$ thick. The preserved sponge in ethanol is completely black in color with dark-discolored ethanol. The conules on the sponge surface are bluntly rounded in shape, compressible and rubbery. The individual conules measure about $2-5 \mathrm{~mm}$. The sponge skeleton consists of irregular and scattered fibers composed of pith. The outline and branching were irregular with thickness measuring between 80 and $300 \mu \mathrm{m}$. The sponge is similar to the sample collected in Red Sea from Eritrea. The sponge voucher $(10.0 \times 4.0 \times 1.0 \mathrm{~cm})$ was kept in the Zoological Museum of the University of Amsterdam with reference no. 17951. A similar specimen of the sponge was kept at Suez Canal University with collection reference DY-61. Collected specimens were kept on ice after collection. After returning to our laboratory, the specimens were freeze-dried (Figure 1) and transferred to the bioanalytical laboratories at TU Bergakademie Freiberg (Freiberg, Germany).

\subsection{Isolation of Chitin from P. Arabica}

The isolation of chitin scaffolds from P. arabica (Figure 1) was carried out according to our previous reports [12,40,52]. The methodology consists of four steps (Figure 11): first, the skeleton of P. arabica was incubated in deionized water at room temperature for one hour to remove possible water-soluble sediment particles and salts. In the second step, the samples were treated with $3 \mathrm{M} \mathrm{HCl}$ at room temperature for $6 \mathrm{~h}$ in order to eliminate possible residual calcium carbonate-based debris (micro fragments of crustacean carapaces and mollusc shells) from the skeleton of P. arabica. Afterwards, the samples were washed several times with deionized water until achieving a $\mathrm{pH}$ of 6.5 followed by treatment with $2.5 \mathrm{M} \mathrm{NaOH}$ at $37{ }^{\circ} \mathrm{C}$ for $72 \mathrm{~h}$ to remove pigments and proteins. Due to the observation of the foreign spicules and their fragments in the samples after $72 \mathrm{~h}$ of alkali treatment, additional desilicification was needed. Consequently, alkali-treated samples were accurately rinsed with deionized water and stored in a plastic vessel containing appropriate amount of $10 \%$ hydrofluoric acid (HF) solution (step four). The vessel was covered in order to prevent the evaporation of HF. The desilicification process was conducted at room temperature for $12 \mathrm{~h}$. The influence of alkaline and strong acidic treatments on the structure of skeleton of the studied sponge was investigated using stereo, white light and fluorescence microscopy. Finally, the isolated material was washed several times with deionized water up to a $\mathrm{pH}$ level of 6.5. The fibrous translucent scaffolds (Figure 2) were placed into $250 \mathrm{~mL}$ large GLS 80 Duran glass bottles containing deionized water and stored at $4{ }^{\circ} \mathrm{C}$ for further analyses.

\subsection{Light and Fluorescent Microscopy Analyses and Imaging}

Collected sponge samples and isolated chitinous scaffolds were observed using BZ-9000 microscope (Keyence, Osaka, Japan) in the light as well as in the fluorescent microscopy modus.

\subsection{Scanning Electron Microscopy Analysis}

The morphology and microstructure of isolated and purified chitinous scaffolds, as well as untreated samples of P. arabica, were studied on the basis of SEM images using a Philips ESEM XL 30 scanning electron microscope (FEI Company, Peabody, MA, USA). Before analysis, samples were covered with a carbon layer for one minute using an Edwards S150B sputter coater (BOC Edwards, Wilmington, MA, USA). 


\subsection{Calcofluor White Staining Test}

Due to the fact that Calcofluor White (Fluorescent Brightener M2R, Sigma-Aldrich, Taufkirchen, Germany) exhibits enhanced fluorescence after binding to chitin [53,54], this staining method was applied to investigate the location of chitin in the completely purified fibers of $P$. arabica. The selected chitinous fibers were soaked in $0.1 \mathrm{M} \mathrm{KOH}$-glycerine-water solution and few drops of the $0.1 \% \mathrm{CFW}$ solution were added. This mixture was incubated for $3 \mathrm{~h}$ in darkness, washed several times with demineralized water, dried at room temperature and examined using BZ-9000 microscope (Keyence, Osaka, Japan).

\subsection{FTIR and Raman Spectroscopy}

FTIR spectra of chitinous scaffolds were acquired using a Nicolet 210c FTIR spectrometer. The samples were analysed using the ATR system with resolution equals $4 \mathrm{~cm}^{-1}$. A micro-Raman system composed by a spectrometer (RamanRxn1 ${ }^{\mathrm{TM}}$, Kaiser Optical Systems Inc., Ann Arbor, MI, USA), a $785 \mathrm{~nm}$ excitation laser diode (Invictus 785, Kaiser Optical Systems Inc., Ann Arbor, MI, USA) and an upright microscope (DM2500 P, Leica Microsystems GmbH, Wetzlar, Germany) was used to acquire the Raman spectra from the sample surface. Each spectrum was registered in the range 150-3250 $\mathrm{cm}^{-1}$ with resolution of $4 \mathrm{~cm}^{-1}$, using a total acquisition time of $80 \mathrm{~s}$. The fluorescence background was subtracted in MATLAB (MathWorks Inc., Natick, MA, USA) with a baseline procedure.

\subsection{Chitinase Digestion Test}

Yatalase ${ }^{\circledR}$ from culture supernatants of Corynebacterium sp. OZ-21 (Cosmo Bio, Tokyo, Japan) was used for the digestion test. Yatalase is a complex enzyme, consisting mainly of chitinase, chitobiase and $\beta$-1,3-glucanase. One unit of this enzyme released one $\mu$ mol of $N$-acetylglucosamine from $0.5 \%$ chitin solution and $1 \mu \mathrm{mol}$ of $\mathrm{p}$-nitrophenol from p-nitrophenyl- $N$-acetyl- $\beta$ - $D$-glucosaminide solution in $1 \mathrm{~min}$ at $37^{\circ} \mathrm{C}$ and $\mathrm{pH}$ 6.0. The selected, completely demineralized chitinous scaffolds of P. arabica (Figure 3) were incubated in an enzyme solution containing $10 \mathrm{mg} / \mathrm{mL}$ Yatalase dissolved in phosphate buffer at $\mathrm{pH} 6.0$ for $2 \mathrm{~h}$. The progress of digestion was monitored under light microscopy using BZ-9000 microscope (Keyence, Osaka, Japan).

\subsection{Estimation of N-Acetyl-D-Glucosamine (NAG) Content and Electrospray Ionization Mass Spectrometry (ESI-MS)}

The Morgan-Elson assay was used in order to evaluate the $N$-acetyl-D-glucosamine released after chitinase treatment, as described previously. For more details see $[6,11,12]$.

Sample preparation for the ESI-MS analysis was performed by the hydrolysis of organic matrixes obtained after HF-treatment of the biological samples in $6 \mathrm{M} \mathrm{HCl}\left(24 \mathrm{~h}\right.$ at $\left.90^{\circ} \mathrm{C}\right)$. The samples, after $\mathrm{HCl}$ hydrolysis were filtrated with a 0.4 micron filter and freeze-dried in order to remove any excess $\mathrm{HCl}$. The standard D-glucosamine as a control was purchased from Sigma (Sigma-Aldrich, Taufkirchen, Germany Both the commercial standard and the prepared sample were dissolved in water before ESI-MS analysis. ESI-MS measurements were performed on an Agilent Technologies 6230 TOF LC/MS spectrometer (Applied Biosystems, Foster City, CA, USA) in line as a detector in the analytical HPLC instrument. Nitrogen was used as the nebulizing and desolation gas.

\section{Conclusions}

The results of this investigation showed the need to develop new, simultaneous, more effective methods of extraction of both biologically active compounds and chitinous scaffolds from P. arabica and other species. The possibility of farming of Pseudoceratina species from primmorph-based cultures and under marine ranching conditions possesses high potential for advanced blue biotechnology. Due to the fact that, the P. arabica species live at low depths (around $10 \mathrm{~m}$ ) development of a new method for their aquaculture in tropical areas become very attractive from the industrial and economical 
point of view. It is already confirmed that chitinous scaffolds isolated from representatives of the order Verongiida are lucrative for the development of regenerative medicine. Further research could also be conducted to determine the possibility of technological application of chitinous scaffolds of P. arabica origin as advanced 3D composite materials under conditions of extreme biomimetics or adsorbents. We suggest that this study will trigger the future research dedicated to both (i) discovery of chitin within other representatives of the family Pseudoceratinidae (ii) and their utilization in modern technologies improving the quality of human life and health.

Author Contributions: H.E., T.J., Y.J., L.A.S., and S.Ż.-A. designed the study protocol and wrote the manuscript; D.T.A.Y. collected the sponge materials; L.A.S., H.Z.A., D.T.A.Y., M.T., L.V.M., O.B.S., R.G., K.T., V.N.I., and I.P. prepared samples and performed chemical characterization of chitin from P. arabica; R.M., N.B., H.M., and M.W. conducted SEM and other microscopy investigations and analyzed the data. All the authors critically reviewed and approved the final version of the manuscript.

Funding: This work was partially supported by DFG Project HE 394/3-2 (Germany) and PUT Research Grant no. 03/32/DSMK/0810 (Poland). Marcin Wysokowski was supported by Foundation for Polish Science-START 097.2017 and Sonia Żółtowska-Aksamitowska was supported by DAAD as well as Erasmus Plus programs. A special thanks for technical assistance and discussions goes to BromMarin GmbH and INTIB GmbH (Germany). There was no additional external funding received for this study.

Conflicts of Interest: The authors declare no conflict of interest.

\section{References}

1. Bengtson, S.; Rasmussen, B.; Ivarsson, M.; Muhling, J.; Broman, C.; Marone, F.; Stampanoni, M.; Bekker, A. Fungus-like mycelial fossils in 2.4-billion-year-old vesicular basalt. Nat. Ecol. Evol. 2017, 1, 0141. [CrossRef]

2. Wysokowski, M.; Petrenko, I.; Stelling, A.L.; Stawski, D.; Jesionowski, T.; Ehrlich, H. Poriferan chitin as a versatile template for extreme biomimetics. Polymers 2015, 7, 235-265. [CrossRef]

3. Roberts, G.A.F. Chitin Chemistry; MacMillian: London, UK, 1992.

4. Ehrlich, H. Chitin and collagen as universal and alternative templates in biomineralization. Int. Geol. Rev. 2010, 52, 661-669. [CrossRef]

5. Kaya, M.; Mujtaba, M.; Ehrlich, H.; Salaberria, A.M.; Baran, T.; Amemiya, C.T.; Galli, R.; Akyuz, L.; Sargin, I.; Labidi, J. On chemistry of $\gamma$-chitin. Carbohydr. Polym. 2017, 176, 177-186. [CrossRef] [PubMed]

6. Ehrlich, H.; Malando, M.; Spindler, K.D.; Eckert, C.; Hanke, T.; Born, R.; Goebel, C.; Simon, P.; Heinemann, S.; Worch, H. First evidence of chitin as a component of the skeletal fibers of marine sponges. Part I. Verongidae (Demospongia: Porifera). J. Exp. Zool. B Mol. Dev. Evol. 2007, 308, 347-356. [CrossRef]

7. Ehrlich, H.; Krautter, M.; Hanke, T.; Simon, P.; Knieb, C.; Heinemann, S.; Worch, H. First Evidence of the presence of chitin in skeletons of marine sponges. Part II. Glass sponges (Hexactinellida: Porifera). J. Exp. Zool. B Mol. Dev. Evol. 2007, 306, 473-483. [CrossRef]

8. Brunner, E.; Richthammer, P.; Ehrlich, H.; Paasch, S.; Simon, P.; Ueberlein, S.; van Pée, K.H. Chitin-based organic networks: An integral part of cell wall biosilica in the diatom Thalassiosira pseudonana. Angew. Chem. Int. Ed. 2009, 48, 9724-9727. [CrossRef] [PubMed]

9. Rahman, M.A.; Halfar, J. First evidence of chitin in calcified coralline algae: New insights into the calcification process of Clathromorphum compactum. Sci. Rep. 2014, 4, 6162. [CrossRef]

10. Ehrlich, H.; Shaala, L.A.; Youssef, D.T.A.; Żoltowska-Aksamitowska, S.; Tsurkan, M.; Galli, R.; Meissner, H.; Wysokowski, M.; Petrenko, I.; Tabachnick, K.R.; et al. Discovery of chitin in skeletons of non-verongiid Red Sea demosponges. PLoS ONE 2018, 13, e0195803. [CrossRef] [PubMed]

11. Ehrlich, H.; Kaluzhnaya, O.V.; Tsurkan, M.V.; Ereskovsky, A.; Tabachnick, K.R.; Ilan, M.; Stelling, A.; Galli, R.; Petrova, O.V.; Nekipelov, S.V.; et al. First report on chitinous holdfast in sponges (Porifera). Proc. Biol. Sci. 2013, 280, 20130339. [CrossRef]

12. Ehrlich, H.; Kaluzhnaya, O.V.; Brunner, E.; Tsurkan, M.V.; Ereskovsky, A.; Ilan, M.; Tabachnick, K.R.; Bazhenov, V.V.; Paasch, S.; Kammer, M.; et al. Identification and first insights into the structure and biosynthesis of chitin from the freshwater sponge Spongilla lacustris. J. Struct. Biol. 2013, 183, 474-483. [CrossRef] [PubMed] 
13. Brunner, E.; Ehrlich, H.; Schupp, P.; Hedrich, R.; Hunoldt, S.; Kammer, M.; Machill, S.; Paasch, S.; Bazhenov, V.V.; Kurek, D.V.; et al. Chitin-based scaffolds are an integral part of the skeleton of the marine demosponge Ianthella basta. J. Struct. Biol. 2009, 168, 539-547. [CrossRef] [PubMed]

14. Ehrlich, H.; Steck, E.; Ilan, M.; Maldonado, M.; Muricy, G.; Bavestrello, G.; Kljajic, Z.; Carballo, J.L.; Schiaparelli, S.; Ereskovsky, A.; et al. Three-dimensional chitin-based scaffolds from Verongida sponges (Demospongiae: Porifera). Part II. Biomimetic potential and applications. Int. J. Biol. Macromol. 2010, 47, 141-145. [CrossRef] [PubMed]

15. Ehrlich, H.; Ilan, M.; Maldonado, M.; Muricy, G.; Bacestrello, G.; Kljajic, Z.; Carballo, J.L.; Schiaparelli, R.; Ereskovsky, A.; Schupp, P.; et al. Three-dimensional chitin-based scaffolds from Verongida sponges (Demospongiae: Porifera). Part I. Isolation and identification of chitin. Int. J. Biol. Macromol. 2010, 47, 132-140. [CrossRef] [PubMed]

16. Schleuter, D.; Günther, A.; Paasch, S.; Ehrlich, H.; Kljajić, Z.; Hanke, T.; Bernhard, G.; Brunner, E. Chitin-based renewable materials from marine sponges for uranium adsorption. Carbohydr. Polym. 2013, 92, 712-718. [CrossRef] [PubMed]

17. Mutsenko, V.V.; Bazhenov, V.V.; Rogulska, O.; Tarusin, D.N.; Schütz, K.; Brüggemeier, S.; Gossla, E.; Akkineni, A.R.; Meissner, H.; Lode, A.; et al. 3D chitinous scaffolds derived from cultivated marine demosponge Aplysina aerophoba for tissue engineering approaches based on human mesenchymal stromal cells. Int. J. Biol. Macromol. 2017, 104, 1966-1974. [CrossRef] [PubMed]

18. Mutsenko, V.V.; Gryshkov, O.; Lauterboeck, L.; Rogulska, O.; Tarusin, D.N.; Bazhenov, V.V.; Schütz, K.; Brüggemeier, S.; Gossla, E.; Akkineni, A.R.; et al. Novel chitin scaffolds derived from marine sponge Ianthella basta for tissue engineering approaches based on human mesenchymal stromal cells: Biocompatibility and cryopreservation. Int. J. Biol. Macromol. 2017, 104, 1955-1965. [CrossRef]

19. Stepniak, I.; Galinski, M.; Nowacki, K.; Wysokowski, M.; Jakubowska, P.; Bazhenov, V.V.; Leisegang, T.; Ehrlich, H.; Jesionowski, T. A novel chitosan/sponge chitin origin material as a membrane for supercapacitors-Preparation and characterization. RSC Adv. 2016, 6, 4007-4013. [CrossRef]

20. Ehrlich, H.; Simon, P.; Motylenko, M.; Wysokowski, M.; Bazhenov, V.V.; Galli, R.; Stelling, A.L.; Stawski, D.; Ilan, M.; Stöcker, H.; et al. Extreme Biomimetics: Formation of zirconium dioxide nanophase using chitinous scaffolds under hydrothermal conditions. J. Mater. Chem. B 2013, 1, 5092-5099. [CrossRef]

21. Wysokowski, M.; Motylenko, M.; Bazhenov, V.V.; Stawski, D.; Petrenko, I.; Ehrlich, A.; Behm, T.; Kljajic, Z.; Stelling, A.L.; Jesionowski, T.; et al. chitin as a template for hydrothermal zirconia deposition. Front. Mater. Sci. 2013, 7, 248-260. [CrossRef]

22. Wysokowski, M.; Motylenko, M.; Beyer, J.; Makarova, A.; Stöcker, H.; Walter, J.; Galli, R.; Kaiser, S.; Vyalikh, D.; Bazhenov, V.V.; et al. Extreme biomimetic approach for developing novel chitin- $\mathrm{GeO}_{2}$ nanocomposites with photoluminescent properties. Nano Res. 2015, 8, 2288-2301. [CrossRef]

23. Petrenko, I.; Bazhenov, V.V.; Galli, R.; Wysokowski, M.; Fromont, J.; Schupp, P.J.; Stelling, A.L.; Niederschlag, E.; Stöker, H.; Kutsova, V.Z.; et al. Chitin of poriferan origin and the bioelectrometallurgy of copper/copper oxide. Int. J. Biol. Macromol. 2017, 104, 1626-1632. [CrossRef]

24. Harper, M.K.; Bugni, T.S.; Copp, B.R.; James, R.D.; Lindsay, B.S.; Richardson, A.D.; Schnabel, P.C.; Tasdemir, D.; van Wagoner, R.M.; Verbitski, S.M. Introduction to the chemical ecology of marine natural products. In Marine Chemical Ecology; McClintock, J.B., Baker, B.J., Eds.; CRC Press LLC: Boca Raton, FL, USA, 2011; pp. 3-70.

25. Bergquist, P.R.; Wells, R.J. Chemotaxonomy of the Porifera: The development and current status of the field. In Marine Natural Products. Chemical and Biological Perspectives; Scheue, P.J., Ed.; Academic Press: New York, NY, USA, 1983; Volume V, pp. 1-50.

26. Bergquist, P.R.; Hofheinz, W.; Oesterhelt, G. Sterol composition and the classification of the demospongiae. Biochem. Syst. Ecol. 1991, 19, 17-24. [CrossRef]

27. Shaala, L.A.; Bamane, F.H.; Badr, J.M.; Youssef, D.T.A. Brominated arginine-derived alkaloids from the red sea sponge Suberea mollis. J. Nat. Prod. 2011, 74, 1517-1520. [CrossRef] [PubMed]

28. Shaala, L.A.; Youssef, D.T.A.; Badr, J.M.; Sulaiman, M.; Khedr, A. Bioactive secondary metabolites from the Red Sea marine Verongid sponge Suberea species. Mar. Drugs 2015, 13, 1621-1631. [CrossRef] [PubMed]

29. Shaala, L.A.; Youssef, D.T.A.; Sulaiman, M.; Behery, F.A.; Foudah, A.I.; El Sayed, K.A. Subereamolline A as a potent breast cancer migration, invasion and proliferation inhibitor and bioactive dibrominated alkaloids from the red sea sponge Pseudoceratina arabica. Mar. Drugs 2012, 10, 2492-2508. [CrossRef] [PubMed] 
30. Shaala, L.A.; Youssef, D.T.A.; Badr, J.M.; Sulaiman, M.; Khedr, A.; El Sayed, K.A. Bioactive alkaloids from the Red Sea marine Verongid sponge Pseudoceratina arabica. Tetrahedron 2015, 71, 7837-7841. [CrossRef]

31. Shaala, L.A.; Khalifa, S.I.; Mesbah, M.K.; van Soest, R.W.M.; Youssef, D.T.A. Subereaphenol A, a new cytotoxic and antimicrobial dibrominated phenol from the red sea sponge Suberea mollis. Nat. Prod. Commun. 2008, 3, 219-222.

32. Żółtowska-Aksamitowska, S.; Shaala, L.A.; Youssef, D.T.A.; Elhady, S.S.; Tsurkan, M.V.; Petrenko, I.; Wysokowski, M.; Tabachnick, K.; Meissner, H.; Ivanenko, V.N.; et al. First report on chitin in a non-verongiid marine demosponge: The Mycale euplectellioides case. Mar. Drugs 2018, 16, 68. [CrossRef]

33. Żółtowska-Aksamitowska, S.; Tsurkan, M.V.; Lim, S.C.; Meissner, H.; Tabachnick, K.; Shaala, L.A.; Youssef, D.T.A.; Ivanenko, V.N.; Petrenko, I.; Wysokowski, M.; et al. The demosponge Pseudoceratina purpurea as a new source of fibrous chitin. Int. J. Biol. Macromol. 2018, 112, 1021-1028. [CrossRef] [PubMed]

34. Bechmann, N.; Ehrlich, H.; Eisenhofer, G.; Ehrlich, A.; Meschke, S.; Ziegler, C.G.; Bornstein, S.R. Anti-tumorigenic and anti-metastatic activity of the sponge-derived marine drugs aeroplysinin- 1 and isofistularin-3 against pheochromocytoma in vitro. Mar. Drugs 2018, 16, 172. [CrossRef] [PubMed]

35. Karuso, P. Chemical ecology of the nudibranchs. Bioorg. Med. Chem. 1987, 1, 31-60.

36. Tabudravu, J.N.; Eijsink, V.G.H.; Gooday, G.W.; Jaspars, M.; Komander, D.; Legg, M.; Synstad, B.; Van Aalten, D.M.F. Psammaplin A, a chitinase inhibitor isolated from the Fijian marine sponge Aplysinella rhax. Bioorg. Med. Chem. 2002, 10, 1123-1128. [CrossRef]

37. Abbas, A.T.; Shaala, L.A.; Ali, S.S.; Azhar, E.I.; Abdel-Dayem, U.A.; El-Shitany, N.A.; Youssef, D.T.A. Assessment of protective effects of the Red Sea Sponge Suberea mollis against $\mathrm{CCl}_{4}$-induced acute liver injury in rats. Evid.-Based Complement. Altern. Med. 2014, 3, 745606. [CrossRef]

38. Abu-Shoer, M.I.; Shaala, L.A.; Youssef, D.T.A.; Badr, J.M.; Habib, A.M. Bioactive brominated metabolites from the Red Sea sponge Suberea mollis. J. Nat. Prod. 2008, 71, 1464-1467. [CrossRef] [PubMed]

39. Ehrlich, H.; Bazhenov, V.V.; Meschke, S.; Burger, M.M.; Ehrlich, A.; Petovic, S.; Durovic, M. Marine invertebrates of Boka Kotorska Bay unique sources for bioinspired materials science. In The Boka Kotorska Bay Environment, Series: The Handbook of Environmental Chemistry; Djurović, M., Semenov, A., Zonn, I., Kostianoy, A., Eds.; Springer: Berlin/Heidelberg, Germany, 2016; pp. 313-334.

40. Ehrlich, H.; Bazhenov, V.V.; Debitus, C.; de Voogd, N.; Galli, R.; Tsurkan, M.V.; Wysokowski, M.; Meissner, H.; Bulut, E.; Kaya, M.; et al. Isolation and identification of chitin from heavy mineralized skeleton of Suberea clavata (Verongida: Demospongiae: Porifera) marine demosponge. Int. J. Biol. Macromol. 2017, 104, 1706-1712. [CrossRef] [PubMed]

41. Wysokowski, M.; Zatoń, M.; Bazhenov, V.V.; Behm, T.; Ehrlich, A.; Stelling, A.L.; Hog, M.; Ehrlich, H. Identification of chitin in 200-million-year-old gastropod egg capsules. Paleobiology 2014, 40, 529-540. [CrossRef]

42. Kumirska, J.; Czerwicka, M.; Kaczyński, Z.; Bychowska, A.; Brzozowski, K.; Thoming, J.; Stepnowski, P. Application of spectroscopic methods for structural analysis of chitin and chitosan. Mar. Drugs 2010, 8 , 1567-1636. [CrossRef] [PubMed]

43. Galat, A.; Popowicz, J. Study of the Raman scattering spectra of chitins. Bull. Acad. Pol. Sci. Ser. Sci. Biol. 1987, 26, 519-524.

44. De Gussem, K.; Vandenabeele, P.; Verbeken, A.; Moens, L. Raman spectroscopic study of Lactarius spores (Russulales, Fungi). Spectrochim. Acta Part A Mol. Biomol. Spectrosc. 2005, 61, 2896-2908. [CrossRef]

45. Ehrlich, H.; Maldonado, M.; Parker, A.R.; Kulchin, Y.N.; Schilling, J.; Köhler, B.; Skrzypczak, U.; Simon, P.; Reiswig, H.M.; Tsurkan, M.V.; et al. Supercontinuum generation in naturally occurring glass sponges spicules. Adv. Opt. Mater. 2016, 4, 1608-1613. [CrossRef]

46. Nickerl, J.; Tsurkan, M.; Neinhuis, C.; Werner, C. The multilayered protective cuticle of Collembola: A chemical analysis. J. R. Soc. Interface 2014, 11, 20140619. [CrossRef] [PubMed]

47. Ehrlich, H.; Rigby, J.K.; Botting, J.P.; Tsurkan, M.V.; Werner, C.; Schwille, P.; Petrášek, Z.; Pisera, A.; Simon, P.; Sivkov, V.N.; et al. Discovery of 505-million-year old chitin in the basal demosponge Vauxia gracilenta. Sci. Rep. 2013, 3, 17-20. [CrossRef] [PubMed]

48. Bergquist, P.R.; Kelly-Borges, M. Systematics and biogeography of the genus Ianthella (Demospongiae: Verongida: Ianthellidae) in the South-West Pacific. The Beagle. Rec. Museums Art Gall. North. Territ. 1995, 12, 151-176. 
49. Erwin, P.M.; Thacker, R.W. Phylogenetic analyses of marine sponges within the order Verongida: A comparison of morphological and molecular data. Invertebr. Biol. 2007, 126, 220-234. [CrossRef]

50. Thompson, J.E.; Barrow, K.D.; Faulkner, D.J. Localization of two brominated metabolites, aerothionin and homoaerothionin, in spherulous cells of the marine sponge Aplysina fistularis (=Verongia thiona). Acta Zool. 1983, 64, 199-210. [CrossRef]

51. Jesionowski, T.; Norman, M.; Żółtowska-Aksamitowska, S.; Petrenko, I.; Joseph, Y.; Ehrlich, H. Marine spongin: Naturally prefabricated 3D scaffold-based biomaterial. Mar. Drugs 2018, 16, 88. [CrossRef]

52. Wysokowski, M.; Bazhenov, V.V.; Tsurkan, M.V.; Galli, R.; Stelling, A.L.; Stöcker, H.; Kaiser, S.; Niederschlag, E.; Gärtner, G.; Behm, T.; et al. Isolation and identification of chitin in three-dimensional skeleton of Aplysina fistularis marine sponge. Int. J. Biol. Macromol. 2013, 62, 94-100. [CrossRef]

53. Monheit, J.E.; Cowan, D.F.; Moore, D.G. Rapid detection of fungi in tissues using Calcofluor White and fluorescence microscopy. Arch. Pathol. Lab. Med. 1984, 108, 616-618.

54. Hickey, P.C.; Swift, S.R.; Roca, M.G.; Read, N.D. Live-cell imaging of filamentous fungi using vital fluorescent dyes and confocal microscopy. Methods Microbiol. 2004, 34, 63-87.

(C) 2019 by the authors. Licensee MDPI, Basel, Switzerland. This article is an open access article distributed under the terms and conditions of the Creative Commons Attribution (CC BY) license (http://creativecommons.org/licenses/by/4.0/). 